\title{
Vigilancia del virus de Influenza Aviar tipo A en patos de crianza familiar de las provincias de Huaral y Huaura (Lima, Perú)
}

\section{Surveillance of Avian Influenza type A virus in backyard ducks of the provinces of Huaral and Huaura (Lima, Peru)}

\author{
Jenny Valladares G. ${ }^{1,3}$, Eliana Icochea D. ${ }^{1,4}$, Rosa González V. ${ }^{1}$, María Silva I. ${ }^{2}$
}

\section{Resumen}

\begin{abstract}
El objetivo del estudio fue evaluar la presencia del virus de influenza aviar (IA) en patos domésticos de crianza familiar en las provincias de Huaral y Huaura (Lima, Perú). Se colectaron 600 muestras de hisopado cloacal de patos domésticos de traspatio, que fueron analizadas mediante aislamiento viral en huevos embrionados de pollo libres de patógenos específicos (SPF). La presencia del virus de IA fue determinada por la actividad hemaglutinante del fluido alantoideo y confirmada mediante un kit comercial que utiliza anticuerpos monoclonales. Todas las muestras analizadas fueron negativas al virus de IA. El riego de infección fue evaluado mediante la simulación de Monte Carlo (programa@risk) determinando que el virus de IA mostraría una prevalencia estocástica máxima de $0.33 \%$ con un intervalo de confianza de $95 \%$ en caso de presentarse la enfermedad. Se concluye que las aves incluidas en el presente estudio no se encontraban infectadas con el virus de IA.
\end{abstract}

Palabras clave: virus de influenza aviar; patos domésticos

\section{AbSTRACT}

The aim of this study was to evaluate the presence of avian influenza (AI) virus in backyard domestic ducks in the provinces of Huaral and Huaura (Lima, Peru). Six-hundred cloacal swab specimens were collected and analyzed by virus isolation in chick embryo eggs free from specific pathogens (SPF). The presence of the AI virus was determined by the hemagglutinating activity of the allantoic fluid and confirmed by a commercial kit

\footnotetext{
${ }^{1}$ Laboratorio de Patología Aviar, Facultad de Medicina Veterinaria, Universidad Nacional Mayor de San Marcos, Lima, Perú

${ }^{2}$ Destacamento Naval de Investigación Médica (NMRCD), Lima, Perú

${ }^{3}$ E-mail: jenny.valladares90@gmail.com

${ }^{4}$ E-mail: eliana.icochea@gmail.com
}

Recibido: 5 de abril de 2017

Aceptado para publicación: 15 de agosto de 2017 
using monoclonal antibodies. All samples analyzed were negative to the AI virus. The risk of the disease was evaluated using the Monte Carlo simulation (@risk program) which determined that the AI virus would show a maximum stochastic prevalence of $0.33 \%$ with a $95 \%$ confidence interval in the event of the disease. It was concluded that the birds included in the present study were not infected with the AI virus.

Key words: avian influenza virus; domestic ducks

\section{INTRODUCCIÓN}

Influenza aviar (IA) es una enfermedad infecciosa de las aves causada por el virus de influenza aviar (vIA) tipo A. Esta enfermedad representa un problema de gran importancia en la industria avícola mundial, debido a que genera grandes pérdidas económicas y restricciones al comercio internacional. Los virus de influenza aviar son propensos a mutar constituyendo un potencial riesgo zoonótico que podría ser altamente peligroso para el hombre. Por todo lo anterior, la influenza aviar se encuentra en la lista de enfermedades notificables de la Organización Mundial de Sanidad Animal (OIE, 2017).

Las aves silvestres acuáticas, especialmente las del orden Anseriformes y Charadriiformes, representan el principal reservorio natural de todos los virus de Influenza tipo A, alcanzando un estable estado de adaptación evolutiva y, por lo general, la infección no cursa con sintomatología clínica (Spackman et al., 2005; Olsen et al., 2006). Cuando el virus infecta a un ave doméstica ocurren una adaptación mediante mutaciones genéticas que pueden lograr con éxito su replicación y transmisión (Suarez, 2000). Durante el año 1956, en Checoslovaquia e Inglaterra se documentaron los primeros informes de aislamiento del virus de influenza aviar en patos domésticos, siendo los reconocimientos iniciales de infecciones del virus en aves (Koppel et al., 1956). De forma general, los patos han sido la especie en donde más se han aislado los virus de influenza (Easterday et al., 1997).

En 2004, la Organización de las Naciones Unidas para la Agricultura y la Alimentación (FAO), la Organización Mundial de la Salud (OMS) y la Organización Mundial de Sanidad Animal (OIE) alertaron que los patos domésticos podrían ser portadores silenciosos del virus, teniendo un papel clave en la transmisión horizontal a otras aves y al hombre, dado que hace casi imposible su erradicación al ser generalmente asintomáticos (FAO, 2004). La vigilancia epidemiológica en esta especie ayudaría a una posible detección temprana del virus impidiendo su pronta diseminación.

El Programa Nacional de Sanidad Avícola del SENASA en 2005 elaboró un documento sustentatorio para la declaración del Perú como país libre de la IA (SENASA, 2005), luego de obtener resultados negativos durante la vigilancia que realizó entre 2004 y 2005. En 2016, el SENASA muestreó 27000 aves obteniendo resultados negativos a IA (SENASA, 2017). Así mismo, otros estudios realizados en aves de crianza en el país como parte de la vigilancia de IA han sido negativos (Monasí et al., 1999; Rondón et al., 2013). Estos resultados contribuyen para generar información al sistema de vigilancia epidemiológica de la enfermedad ofreciendo una visión al panorama de un país libre que intenta detectar tempranamente la incursión del virus de IA en sitios de alto riesgo, más aún al confirmarse que aves migratorias analizadas fueron positivas al vIA (Ghersi et al., 2009, 2011; Segovia et al., 2013). 
El objetivo de este estudio fue evaluar la presencia del vIA mediante el aislamiento viral en huevos embrionados SPF a partir de hisopados cloacales de patos domésticos de crianza de traspatio en Huaral y Huaura, dos provincias peruanas donde es común la crianza familiar de esta especie bajo un escaso cuidado veterinario, bajo nivel de bioseguridad y con contactos significativo entre las aves domésticas y silvestres.

\section{Materiales Y MéTOdos}

Se colectaron 600 muestras de hisopado cloacal de patos domésticos de crianza familiar en las provincias de Huaral (distritos de Chancay, Aucallama y Huaral) y Huaura (distritos de Huaura, Sayán, Santa María, Vegueta y Hualmay), ubicadas en el departamento de Lima, Perú. Los patos fueron escogidos al azar sin distinción de edad ni sexo.

El tamaño de muestra se determinó al aplicar el modelo teórico de la distribución binomial, asumiendo que la prevalencia de detección viral para esta especie es de al menos $1 \%$, con base a estudios anteriores en otras aves (González, 1986).

Las muestras fueron conservadas individualmente en medios de cultivo UTM (Universal Transport Medium) e inmediatamente transportadas a $4{ }^{\circ} \mathrm{C}$ al Laboratorio de Patología Aviar de la Facultad de Medicina Veterinaria, Universidad Nacional Mayor de San Marcos, Lima.

Las muestras fueron agrupadas en 60 pooles de 10 muestras cada uno. Cada grupo fue inoculado en cinco huevos embrionados SPF de 9-11 días, vía cavidad alantoidea e incubados durante seis días a $37^{\circ} \mathrm{C}$. Se cosechó el fluido alantoideo y se determinó su actividad hemaglutinante frente a una solución de eritrocitos de pavo al $0.7 \%$. El pool se consideró positivo si al menos uno de los cinco fluidos alantoideos logró aglutinar eritrocitos gracias a las proteínas hemaglutinantes (Horimoto y Kawaoka, 2001).

Todos los fluidos alantoideos con hemaglutinación positiva fueron evaluados en una prueba rápida de ELISA de captura de antígeno (QuickVue ${ }^{\circledR}$ Influenza A+B, Quidel), que es una prueba de inmunoanálisis de flujo lateral, que utiliza anticuerpos monoclonales de alta sensibilidad y especificidad para los antígenos de la influenza A y B. Para descartar la posible presencia de Paramixovirus aviar tipo I (APMV-1), los fluidos alantoideos fueron analizados por inhibición de la hemaglutinación usando un suero conteniendo anticuerpos específicos contra el virus de la enfermedad de Newcastle (vENC) en el Laboratorio de Patología Aviar de la Universidad Nacional Mayor de San Marcos, Lima. Esta prueba se fundamenta en la unión entre el antígeno hemaglutinina y un anticuerpo específico que impide la formación de puentes con el eritrocito resultando en una inhibición de la hemaglutinación (Lupiani y Reddy, 2009). Las muestras con hemaglutinación negativa fueron reanalizadas.

Los datos obtenidos fueron sometidos a la técnica de evaluación de riesgo mediante la simulación Monte Carlo. Las proporciones se expresaron con un intervalo de confianza al $95 \%$. El cálculo de los intervalos se obtuvo al emplearse simulaciones estocásticas basadas en la distribución beta, la cual está implementada en el paquete estadístico@Risk en el entorno de una planilla electrónica Excel XP.

\section{Resultados}

De los 60 pooles analizados, 10 fueron positivos a la prueba de hemaglutinación (Cuadro 1). La prueba de inhibición de la hemaglutinación descartó al virus de Newcastle, indicando la posibilidad de la presencia del vIA. Sin embargo, los resultados obtenidos mediante el ELISA de captura de 
Cuadro 1. Evaluación del fluido alantoideo de huevos SPF embrionados de 9-11 días mediante las pruebas de hemaglutinación e inhibición de la hemaglutinación

\begin{tabular}{llccc}
\hline Provincia & Distrito & $\begin{array}{c}\text { Muestras } \\
(\mathrm{n})\end{array}$ & $\begin{array}{c}\mathrm{HA}+{ }^{1} \\
(\mathrm{n})\end{array}$ & $\begin{array}{c}\mathrm{HI}+{ }^{2} \\
(\mathrm{n})\end{array}$ \\
\hline \multirow{3}{*}{ Huaral } & Aucallama & 78 & 1 & 0 \\
& Chancay & 98 & 4 & 0 \\
& Huaral & 100 & 1 & 0 \\
& 27 de Noviembre & 24 & 0 & 0 \\
& Huacho & 24 & 0 & 0 \\
& Hualmay & 10 & 0 & 0 \\
& Huaura & 82 & 1 & 0 \\
& Santa María & 43 & 0 & 0 \\
& Sayán & 101 & 1 & 0 \\
& Vegueta & 40 & 2 & 0 \\
\hline Total & & 600 & 10 & 0 \\
\hline
\end{tabular}

${ }^{1} \mathrm{HA}+$ : pooles positivos a la prueba de hemoaglutinación

${ }^{2} \mathrm{HI}+$ : pooles positivos a la prueba de inhibición de la hemaglutinación contra el vENC

antígeno resultaron negativos al vIA. Al evaluarse el riesgo mediante la simulación de Monte Carlo se determinó que en caso estar presente la enfermedad de la IA tendría una prevalencia estocástica de $0.33 \%$ con un intervalo de confianza de 0 a $1.5 \%$.

\section{Discusión}

Las muestras de este estudio fueron recolectadas en las provincias de Huaral y Huaura, dos de las provincias con mayor población de patos en el Perú, según registros manejados por el SENASA (J. Pastor, Lima, comunicación personal). Sin embargo, no se realizó una completa selección aleatoria de las muestras debido a que el acceso a los predios de patos de traspatio dependía de la voluntad de los propietarios, siendo una limitante que disminuye la probabilidad de seleccionar un elemento.
Diversos estudios han demostrado que el virus de IA puede ser aislado en humedales, incluso en aquellos con bajas densidades y condiciones ambientales desfavorables y el Perú no ha sido la excepción, aislándose diversas cepas en aves silvestres (Segovia et $a l ., 2013)$. Durante la fase de colección de muestras se pudo constatar la presencia de humedales cercanos a los predios de estudio, donde confluyen aves silvestres que pueden intervenir en la dispersión del virus. Un estudio en Asia demostró la estrecha relación entre la persistencia del virus en humedales y su diseminación a largas distancias al apoyarse en datos de migración de aves silvestres rastreadas por satélite y análisis geoespacial, donde además demostraron que los patos domésticos demarcan las zonas con mayor riesgo de propagación del virus (Gilbert et al., 2010). Por otro lado, algunos de los predios colindaban con granjas porcinas, mientras que en otros se tenía una crianza mixta con estas especies, siendo éste 
un factor de riesgo para la mutación del virus, en caso de estar presente el virus (Bourret, 2017).

Los resultados del presente estudio permiten indicar que el virus de IA no estuvo presente en los patos de traspatio muestreados de las provincias evaluadas; sin embargo, existe la posibilidad que el periodo de muestreo no coincidiera con el tiempo de eliminación viral, o que no se haya logrado aislar el virus en huevos embrionados debido a una baja carga de eliminación viral. El kit de diagnóstico rápido empleado como prueba definitiva ha sido usado para diagnósticos rápidos en humanos y recién en los últimos años, en animales. Un estudio demuestra que la prueba detecta los virus de influenza A sin mostrar falsos positivos, indicando una alta especificidad. No sucede lo mismo con la sensibilidad, donde la detección parece estar relacionada con la carga viral, de modo que títulos inferiores a $2.4 \times 10^{3}$ podrían dar resultados negativos (Kilic et al., 2008).

Otros estudios en aves domésticas muestran grandes variaciones en los resultados de las técnicas diagnósticas, sea debido a la ausencia real del virus o a una baja carga viral. Así, una investigación realizada en aves domésticas en Granada obtuvo resultados positivos a IA al evaluarse sueros sanguíneos mediante la prueba de ELISA y resultados negativos mediante RT-PCR y hemaglutinación al emplearse fluidos alantoideos (Sabarinath et al., 2011). Otra investigación realizada en Perú obtuvo también resultados negativos mediante la prueba de RT-PCR en aves silvestres y domésticas (Ortiz, 2016).

Los resultados de este estudio de hemaglutinación pudieron, por otro lado, ser falsos positivos al virus de Influenza Aviar. Si bien la prueba de hemoaglutinación es esencial en el diagnóstico de los virus de influenza aviar y de enfermedad de Newcastle (ENC), no es específica para estos agentes. Los patos, además de ser susceptibles a los virus de IA, también son susceptibles a otros agentes hemoaglutinantes, principalmente a los Adenovirus tipo 3 (Ataadenovirus causante del síndrome de baja postura) y a varios Paramixovirus aviar, incluyendo al Paramixovirus aviar serotipo 1 (Alexander, 2003; Hafez, 2011). En este estudio, debido a no contarse con sueros anti-adeno3, el fluido alantoideo de las muestras positivas fue analizado solo para presencia de virus de IA y ENC, resultando negativo a la presencia de estos virus.

Desde su aparición en 1976, el virus del síndrome de baja postura se ha aislado repetidamente en patos y gansos con altos títulos de anticuerpos. Varios autores reportan hasta $88.5 \%$ de casos positivos en patos y $95.2 \%$ en patos BB (Thomas et al., 2007; McConnell y Smyth, 2008; Cha et al., 2013). Actualmente, este virus se encuentra distribuido a nivel mundial en estas especies, pareciendo ser los huéspedes naturales del Atadenovirus (Hafez, 2011). Durante el muestreo, los patos se encontraban aparentemente sanos, sin signos clínicos compatibles con enfermedad, y tampoco se detectaron lesiones en los embriones inoculados con las muestras de hisopados de cloaca, de allí que es probable que la positividad a la hemaglutinación en los 10 pooles de muestras se deba a infecciones subclínicas de Adenovirus tipo 3.

\section{Conclusión}

Los 600 patos domésticos de las provincias de Huaral y Huaura fueron negativos al aislamiento del virus de la influenza aviar, indicando que no se encontraban infectados, y que de haberlo estado, lo estarían con una prevalencia de $0.33 \%$.

\section{Literatura Citada}

1. Alexander D. 2003. Newcastle disease and other avian paramixoviridae infecctions. In: Diseases of poultry. $11^{\text {th }} \mathrm{ed}$. USA: Iowa State University. p 63-87. 
2. Bourret V, Lyall J, Frost S, Teillaud $A$, Smith C, Leclaire S, Fu J, et al. 2017. Adaptation of avian influenza virus to a swine host. Virus Evol 3(1): vex007. doi: 10.1093/ve/vex007

3. Cha S, Kang M, Park CK, Choi KS, Jang HK. 2013. Epidemiology of egg drop syndrome virus in ducks from South Korea. Poult Sci 92: 1783-1789. doi: 10.3382/ps.2013-03067

4. Easterday B, Hinshaw V, Halvorson D. 1997. Influenza. In: Calnek BW (ed). Disease of poultry $10^{\text {th }}$ ed. Ames, USA; Iowa State University Press. p 583-605.

5. [FAO] Organización de las Naciones Unidas para la Alimentación y la Agricultura. 2004. Gripe aviar: los patos domésticos podrían representar un nuevo peligro. Sala de Prensa. [Internet]. Disponible en: http://www.fao.org/ newsroom/es/news/2004/51443/ index.html

6. Ghersi BM, Blazes DL, Icochea EA, González RV, Kochel T, Tinoco YF, Sovero. MM, Lindstron S, Shu B, Klimov A, Gonzales A, Mongtgomery JM. 2009. Avian influenza in wild birds, central coast of Peru. Emerg Infect Dis 15: 935-938. doi: 10.3201/eid1506.080981

7. Ghersi BM, Sovero M, Icochea E, González R, Blazes D, González A, Montgomery J. 2011. Isolation of lowpathogenic $\mathrm{H} 7 \mathrm{~N} 3$ avian influenza from wild birds in Peru. J Wildl Dis 47: 792795. doi: 10.7589/0090-3558-47.3.792

8. Gilbert M, Newman S, Takekawa J, Loth L, Biradar C, Prosser D, Balachandran S, et al. 2011. Flying over an infected landscape: distribution of Highly Pathogenic Avian Influenza H5N1 risk in South Asia and satellite tracking of wild waterfol. Ecohealth 7: 448458. doi: 10.1007/s10393-010-0672-8

9. González A. 1986. Presencia de anticuerpos de Influenza A en aves. Tesis de Médico Veterinario. Lima: Univ. Nacional Mayor de San Marcos.
10. Hafez M. 2011. Avian adenoviruses infections with special attention to inclusion body hepatitis/hidropericardium syndrome and egg drop syndrome. Pak Vet J 31: 85-92.

11. Horimoto T, Kawaoka Y. 2001. Pandemic threat posed by avian influenza A viruses. Clin Microbiol Rev 14: 129149. doi: 10.1128/CMR.14.1.129149.2001

12. Kilic S, McCarthy T, C Gray G. 2008. Influenza $A+B$ kit in detecting avian and swine influenza virus. USA: University of Iowa.

13. Koppel Z, Vrtiak J, Vasil M, Spiesz S. 1956. Mass illness of ducklings in Eastern Slovakia with a clinical picture of infectious sinusitis. Veterinarstvi 6 : 267-268.

14. Lupiani B, Reddy S. 2009. The history of avian influenza. Comp Immunol Microbiol Infect Dis 32: 311-323. doi: 10.1016/j.cimid.2008.01.004

15. McConnell B, Smyth J. 2008. Egg drop syndrome. In: SaifY, Fadly A, Glison J, Mc Dougald L, Nolan L, Swayne D (eds). Diseases of poultry. $12^{\text {th }}$ ed. USA: Blackwell Publ. p 251-290.

16. Monasí F. 1999. Prevalencia de anticuerpos al virus de la influenza aviar en broilers en la provincia de Huaral, Lima. Tesis de Médico Veterinario. Lima: Univ Nacional Mayor de San Marcos. 44 p.

17. [OIE] Organización Mundial de Sanidad Animal. 2017. Preguntas y respuestas sobre la influenza aviar. Paris: OIE. Portal sobre la Influenza Aviar. [Internet]. Disponible en: http:// www.oie.int/es/sanidad-animal-en-elmundo/web-portal-sobre-la-influenzaaviar/

18. Olsen B, Munster V, Wallensten A, Waldenström $J$, Osterhaus A, Fouchier R. 2006. Global patterns of Influenza A virus in wild birds. Science 312: 384-388. doi: 10.1126/science.1122438 
19. Ortiz R. 2016. El virus de influenza aviar y de enfermedad de Newcastle en aves silvestres y domésticas tipo traspatio comercializadas en 11 mercados de Lima Metropolitana. Tesis de Médico Veterinario. Lima: Univ. Científica del Sur. 111 p.

20. Rondón JE, Icochea E, González AZ, González R. 2013. Vigilancia dirigida de influenza aviar en aves silvestres usando patos domésticos (Cairina moschata) como centinelas. Rev Inv Vet Perú 24: 324-336. doi: 10.15381/ rivep.v24i3.2581

21. Sabarinath A, Sabarinath G, Tiwari K, Kumthekar S, Thomas D, Sharma R. 2011. Virological and serological surveillance of avian influenza virus in the birds of Grenada. Poult Sci 8: 579582. doi: 10.3923/ijps.2011.579.582

22. Segovia K, Icochea E, González R, Ghersi B, González A. 2013. Presencia del virus de influenza aviar en las aves silvestres de los humedales de Puerto Viejo, Lima. Rev Inv Vet Perú 24: 98103. doi: 10.15381/rivep.v24i1.1672

23. [SENASA] Servicio Nacional de Sanidad Agraria. 2005. Resolución Jefatural N. ${ }^{\circ}$ 273-2005-AG-SENASA del 30 de diciembre de 2005. Dirección General de Sanidad Animal. Lima. [Internet]. Disponible en: https:// www.senasa.gob.pe/senasa/wp-content/ uploads/2014/11/0610.pdf

24. [SENASA] Servicio Nacional de Sanidad Agraria. 2017. SENASA: Monitoreo preventivo de influenza aviar en playas y perihumedales de Áncash. [Internet]. Disponible en: http:// www.senasa.gob.pe/senasacontigo/ senasa-monitoreo-preventivo-de-influenza-aviar-en-playas-y-perihumedales-deancash/

25. Spackman E, Stallknecht D, Slemons $R$, Winker K, Suárez, D, Scott M, Swayne D. 2005. Phylogenetic analyses of type A influenza genes in natural reservoir species in North America reveals genetic variation. Virus Res 114: 89-100. doi: 10.1016/j.virusres.2005.05.013

26. Suarez D. 2000. Evolution of avian influenza viruses. Vet Microbiol 74: 15-27.

27. Thomas N, Hunter B, Atkinson C. 2007. Infectious diseases of wild birds. USA: Blackwell Publ. 496 p. 